\title{
An Exploration of Play Behaviors in Raven Nestlings
}

\author{
Mathias Osvath, ${ }^{1 *}$ Helena Osvath, ${ }^{1}$ and Rasmus Bååth ${ }^{1}$ \\ ${ }^{1}$ Lund University \\ *Corresponding author (Email: mathias.osvath@lucs.lu.se)
}

Citation - Osvath, M., Osvath, H., \& Bååth, R. (2014). An exploration of play behaviors in raven nestlings Animal Behavior and Cognition, 1(2), 157-165. doi: 10.12966/abc.05.06.2014

\begin{abstract}
Play is widespread among vertebrates. Some animal groups stand out in their play behaviors in levels of complexity, innovativeness, sociality, and volume. Despite the vast phylogenetic distance between corvids, parrots, great apes, and dolphins, all are usually identified as among the most playful. These groups also have several complex cognitive skills in common. There is growing agreement that play has evolved multiple times under different selective pressures in different lineages. As these groups appear similar in their complex play but are separated by considerable evolutionary distance, the similarity is unlikely to result from homology. Far more probable is that the similarity has arisen from convergent or parallel evolution. It is important to conduct comparative ontogenetic play studies on these groups to learn more about what basic processes underlie complex play and whether such play is, indeed, related to complex cognition. Toward that end, we explored the play behavior of raven nestlings over the last ten days before they fledged. We found high levels of play both in terms of instances initiated and duration. The play behaviors were at level with - or above - maintenance behaviors and flight training. Most of the play was object play, but social object play and apparent play contagion was also recorded. The importance of play in developing young ravens is clear. The reasons might be less clear, however play could underlie both object-related and social development.
\end{abstract}

Keywords - Raven play, Avian play, Development of play, Raven ontogeny, Physical cognition

Although play in birds has been investigated much less than in mammals, two bird groups stand out in their playfulness: corvids and parrots (e.g., Ficken, 1977). Among the corvids, ravens have received the most attention to date. They are seen as exceptional players in terms of volume, complexity, and innovativeness (e.g., Ficken, 1977; Gwinner, 1966; Heinrich \& Smolker, 1998). Indeed, their playfulness has been well known through the centuries. For example, in one Native American creation myth, a raven crafted humankind simply because he wanted a play partner (Hassler, 2008). Nevertheless, despite the ample recognition, it remains the case that little is known about raven play.

Konrad Lorenz (1959) thought that ravens have a repertoire of instinctive movements initially uncoupled from any particular situation or environment. In line with this, Gwinner (1966) suggested that ravens' play is a way to connect these task-unspecified movements to particular situations, giving ravens their ability to cope with a wide range of environments; so play is given a pivotal role in ravens' remarkable behavioral flexibility. In modern theory, one might translate this to say that ravens learn the affordances in widely varying environments through play.

One finds an array of proposals on the ultimate causes of play (for a review, see Burghardt, 2005; Graham \& Burghardt, 2010). These range from play as motor training to play as training for unexpected events, play as practice of skills needed in adulthood, and play as social training. None of these explanations seem able to account for the entirety of play. Burghardt (2005) proposed that play is a 
heterogeneous phenomenon that has evolved multiple times under different selective pressures in different lineages. If so, this would help explain why play is so notoriously hard to define. In lieu of any precise definition, Burghardt suggested five broad criteria to which a behavior must adhere: it should be functionally incomplete, spontaneous, different from "serious" behavior in form and timing, repeated without being stereotypical, and occurrent in the absence of severe stress.

One could speculate that, at least in some species, play serves more than one ultimate function. Gwinner may well have been right that play helps ravens identify environmental affordances; but this is unlikely to be the whole story. Ravens seem to learn the behaviors of particular individuals during sessions of play caching: information they later use in "serious" food-caching sessions (Bugnyar, Schwab, Schloegl, Kotrschal, \& Heinrich, 2007). Ravens also share non-functional objects in a playful manner when forming social bonds (Pika \& Bugnyar, 2011).

Ravens and other corvids - as well as several parrot species - are highly encephalized compared to other birds, even as they are considered to be among the most playful of birds. The complexity of play in the large-brained great apes, including humans, is well established (e.g., Pellegrini \& Smith, 2005). Dolphins, too, are highly encephalized and highly complex in their play (e.g., Kuczaj, Makecha, Trone, Paulos, \& Ramos, 2006). All these species engage in the three broad categories of play: locomotor, social, and object. Their play is innovative and highly social. The relationship between brain size and play complexity has been raised several times: to wit, there seems to be a correlation between level of play and the proportional size of the brain (e.g., Diamond \& Bond, 2003; Iwaniuk, Nelson, \& Pellis, 2001; Ortega \& Bekoff, 1987). That said, overall brain size as a predictor of play levels appears too crude: it does not work at any higher taxonomic resolution than classes or orders (e.g., Pellis \& Iwaniuk, 2004). Brain size aside, one finds other - perhaps more relevant - similarities between corvids, parrots, great apes, and dolphins in terms of complex cognition. These groups are strikingly similar in their cognition relative to physical and social skills as well as memory and planning (e.g., Jaakkola, 2012; Marino, 2002; Seed, Emery, \& Clayton, 2009; van Horik, Clayton, \& Emery, 2012), despite being only distantly related: the last common ancestor of birds and mammals lived 300 million years ago, the last common ancestor of corvids and parrots 92 million years ago: close to the 94 million years separating dolphins from apes. An evolutionary perspective might prove fruitful not only for studying complex cognition but also understanding complex play - along with the possible connections between the two.

One way to learn more about such connections is to study the development of play in these groups. If one can establish whether either all or part of their complex play is based on the same - or different - developmental mechanisms, one can then hypothesize whether their play results from parallel or convergent evolution. As said, the levels of play complexity in these groups are unusual among both birds and mammals. It is unlikely to result solely from homology - otherwise, more or less all mammals and birds would have similar levels. It could be a case of convergence, if similar play behavior arises from different developmental mechanisms; or parallelism, if the behavior emerges from the same developmental mechanisms. Insights into these evolutionary processes simultaneously offer insights into the origins of complex play. Postulating at least some common underlying developmental mechanisms may - or may not - prove necessary: mechanisms that have evolved only once, existing in at least rudimentary form no later than in the last common ancestor of birds and mammals. In understanding the evolution of play, the difference between the two options is considerable. The "parallel" option would speak for deep homologies repeatedly reused as a basis for play; the "convergent" option would make play a profoundly heterogeneous phenomenon.

To begin to address such questions, we conducted a limited exploratory study on play behavior in raven nestlings (Corvus corax). There exist a few descriptions and a couple of systematic studies on ontogeny of play in fledged ravens. Heinrich and Smolker (1998) accounted for the diversity of play in young ravens, while Gwinner (1966) noted the innovativeness, imitation, and individual variations in their play, continuing into adulthood. Object caching is sometimes regarded as a form of play behavior; two studies examined the development of object and food caching in young ravens (Bugnyar, Stöwe, \& Heinrich, 2007; Kenward et al., 2011). However, there have been no studies to date on the earliest development of ravens' play as found in the nest, even though Heinrich and Smolker (1998) noted that 
raven chicks appear to manipulate sticks in their nests, while Bugnyar, Stöwe, and Heinrich (2007) parenthetically noted a nesting chick that made pressing or placing behaviors with an object. We are aware of only one other study on play in nestling birds of any species: Pellis (1981) investigated the ontogeny of play in Australian magpies (Gymnorthina tibicen), starting in the nest.

The aim of our study was to explore the extent to which ravens play in the nest in the final weeks before they fledge, as well as the types of play they engage in.

\section{Method}

The study was conducted at Lund University Corvid Cognition Station. We observed three chicks - one female and two males - in their nest for the final ten days before the second bird fledged, beginning approximately 40 days after they hatched. The time period was chosen because, at this stage, the birds are large enough to be observed above the brim of the nest clearly, and the parents spend less time in the nest. A captive pair, both approaching two years old, constructed the nest; this was their first brood. Their aviary was not shared with any other ravens. The area was about $120 \mathrm{~m}^{2}$ and the height five meters; it was enriched with a medium-sized (live) tree as well as stones, branches, and bathing trays. The parents were provided a variety of nutritious food, meeting the protein and vitamin needs of growing chicks.

Observational sessions of the whole nest were video recorded from a distance of 15 meters. Each session lasted about $20 \mathrm{~min}$; several sessions were conducted each day, at various times, distributed evenly between the morning and afternoon hours. The total recording time was $7 \mathrm{hrs}, 1 \mathrm{~min}, 18 \mathrm{~s}$. Each recording of the whole nest was coded at least twice and at most three times: once per each observable nestling serving as focal animal. The total time of focal bird coding was $17 \mathrm{hrs}, 50 \mathrm{~min}$, $46 \mathrm{~s}$; i.e., each individual was observed for an average of a third of this time. The total focal bird coding is not equivalent to three times the total recording time, as not all birds were observable the whole time. Identity of the nestlings could not be established with certainty between sessions: they were not individually marked, so as to avoid stress for the inexperienced parents. However, this did not pose any difficulties in terms of the exploratory and descriptive aims of the study. Variability of behaviors within a session was highly similar to variability between sessions, suggesting that any one individual did not bias overall results (see Results).

\section{Codes and video analysis}

Coding for play, maintenance, flight training, and non-play social behaviors was done frame by frame with ELAN. Inter-rater agreement was high: continuous Cohen's Kappa 0.94 (Bakeman, Quera, \& Gnisci, 2009).

The play categories followed Burghardt's five criteria. The behaviors were functionally incomplete, as they did not lead to any observable or discernable outcome. They appeared spontaneous, as there were no evident environmentally inflicted causes to the behaviors. The behaviors were repeated without being stereotypical; moreover the nest material must have been well-known to the nestlings, which makes exploration a less likely explanation. The behaviors also differed in form and timing from "serious" behaviors seen in adults. The maintenance categories all had immediate biological functions. Flight training is regarded as play by Heinrich and Smolker (1998), however as such training has obvious functional benefits we prefer a more conservative view. The non-play social categories are affiliative behaviors seen in adults in other contexts than play.

The sub-codes for play behaviors were (a) exertion/pulling: grabbing a substrate of the nest and pulling it; (b) biting: gripping a substrate with the beak without any backward or forward movement; (c) pecking: touching a substrate with the tip of the closed beak one or several times; (d) combined manipulation: continuously alternating between pulling, biting, and pecking; (e) non-distinguishable manipulation: manipulation in which substrate movement or movement of the base of the beak was observed, but the exact action was not distinguishable; (f) co-manipulation: two or more chicks manipulated the same object at the same time; this code was used simultaneously with a code for the 
specific manipulation for each individual; and (g) contagious manipulation: one individual, visually oriented towards another, initiated the same type of manipulation as the other did first, up to two seconds later (this was only coded as an instance and did not include duration).

The sub-codes for maintenance behaviors were (i) preening: repeatedly biting and stroking one's own feathers with one's beak; (ii) feeding: receiving food from a parent by having it stuffed into the throat; (iii) beak wiping: stroking the sides of the beak once or repeatedly against a solid substrate; and (iv) sleeping: lying with one's head tucked into one's back feathers, eyes not visible, or otherwise lying with one or both eyes closed.

The sub-codes for non-play social behaviors were (1) bill twining: two individuals biting one another's beak tips or aligning them in contact; and (2) allopreening: one individual repeatedly biting or stroking the feathers of another.

Flight training meant flapping one's wings two or more times in a row.

The codes were arranged into bouts when the behavior was continuously repeated. A pause over two seconds constituted the end of a bout.

\section{Results}

Play amounted to $37.4 \%$ of all the instances of coded behavior. The number of instances of play was higher than for maintenance (35.4\%), flight training (13.6\%), and non-play social behavior (13.6\%). This is also shown in Figure 1, which includes 95\% bootstrap confidence intervals (CI) (Efron, 1979). These CIs were calculated by resampling the dataset 1000 times, assuming the observational sessions are independent and identically distributed, and then taking the $2.5 \%$ and $97.5 \%$ quantiles of the bootstrap distribution of the corresponding statistic.

Total duration of instances was longest in the maintenance category: $71.3 \%$ of overall time. Play came next (19.4\%), followed by flight training (6\%) and non-play social behavior (3.3\%) (see Figure 1).

Sleeping by far had the longest duration of any behavior: $46.5 \%$ of overall time. Excluding sleep, maintenance counted for $46.2 \%$ of overall time, play $36.3 \%$, flight training $11.2 \%$, and non-play social behavior $6.2 \%$.
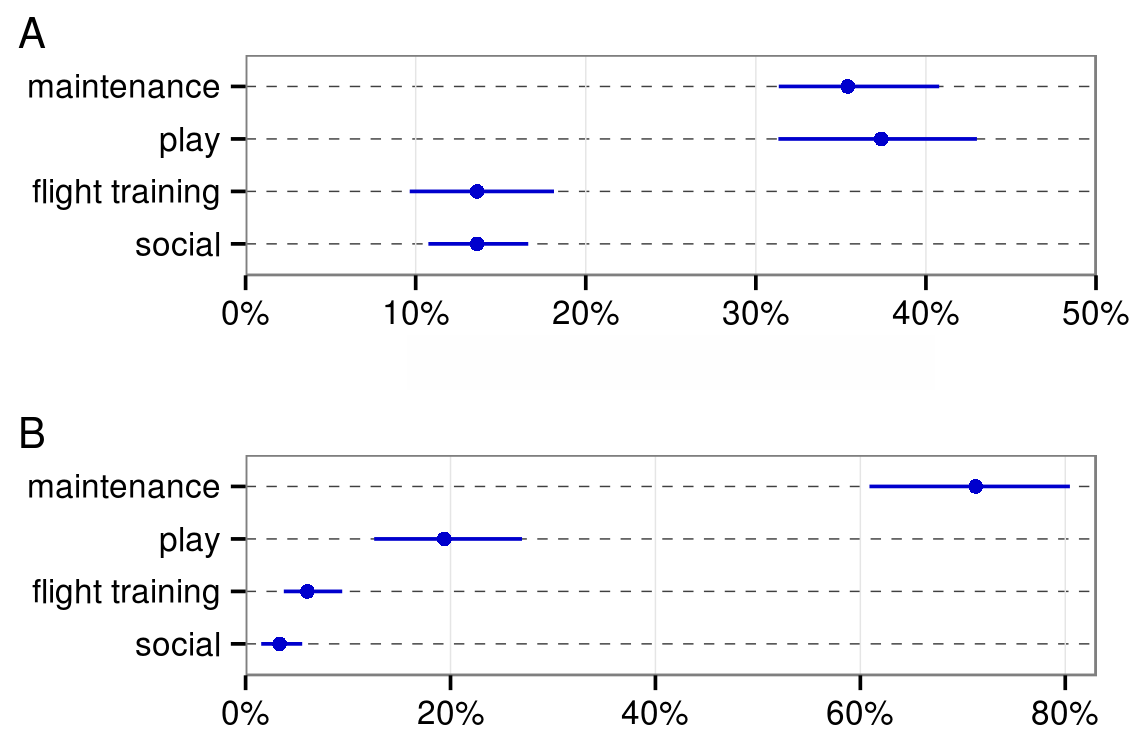

Figure 1. (A) The proportion of the instances of the main behavioral categories out of all the coded instances. (B) The proportion of the duration of the main behavioral categories out of the total duration of all behaviors (note that sleep is included in the maintenance behaviors). The error bars show $95 \%$ bootstrap CIs. 
Figure 2 shows the total duration of instances for each sub-code. In the play category, biting was most frequent: $60.9 \%$ of all instances; while exertion/pulling had the longest duration: $38.6 \%$ of overall play time. Exertion/pulling was comparable to flight training both in instances $(10.3 \%$ vs. $13.6 \%)$ and duration $(7.5 \%$ vs. $6.0 \%)$.

Co-manipulation, which can be described as a form a social object play, comprised $6.7 \%$ of play instances, with a duration of $12.7 \%$ of overall play time. Co-manipulation occurred most often in connection with exertion/pulling. Contagious manipulation - also relating to the social domain, characterized by one individual seemingly following the example of another - comprised $2 \%$ of play instances (duration not measured). The most contagious behavior was exertion/pulling.

Play amounted to $7.6 \%$ of all waking time, maintenance $9.7 \%$ (with preening by far the most frequently occurring: $9.4 \%$ of waking time), flight training $2.4 \%$, and non-play social behavior $1.3 \%$.

See Figure 3 for the proportions of the duration of the main behavioral categories in waking time; and Figure 4 for the proportion of the duration of the sub-codes.

The proportion of time spent on flight training decreased over the course of the ten days of observation (linear regression, the proportion decreased by $0.34 \%$ per day, $95 \%$ CI: $[0.24 \%, 0.44 \%], p<$ 0.001 ). On the first day of observations the duration of flight training amounted to $4 \%$ of the time of the coded behaviors, while on the last day flight training amounted to less than $1 \%$.

We found no asymmetry in levels of activity between individuals. The mean variability within sessions did not differ notably from the total variability in the dataset. The mean of the standard deviation (SD) of percent within-session play behavior was 11.0, compared to a total SD of 11.2. In the remainder of behaviors, the within-session SD was 25.7, compared to a total SD of 25.2.

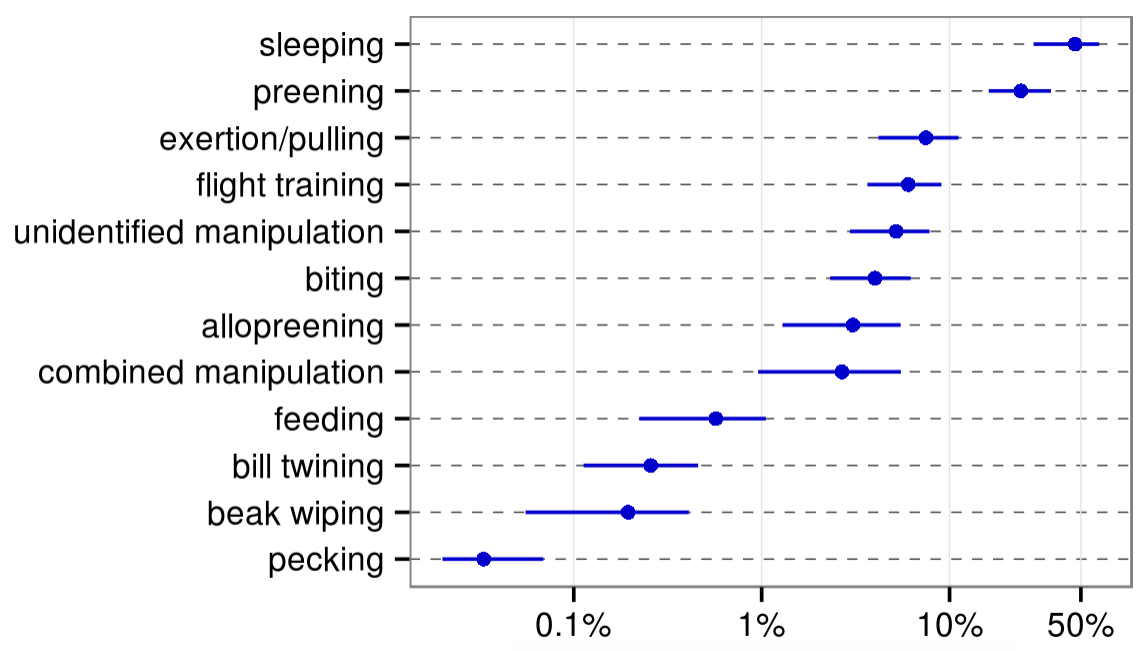

Figure 2. The proportion of the duration of the sub-codes out of the total duration of all instances. The X-axis is log-scaled and the error bars show $95 \%$ bootstrap CIs. 


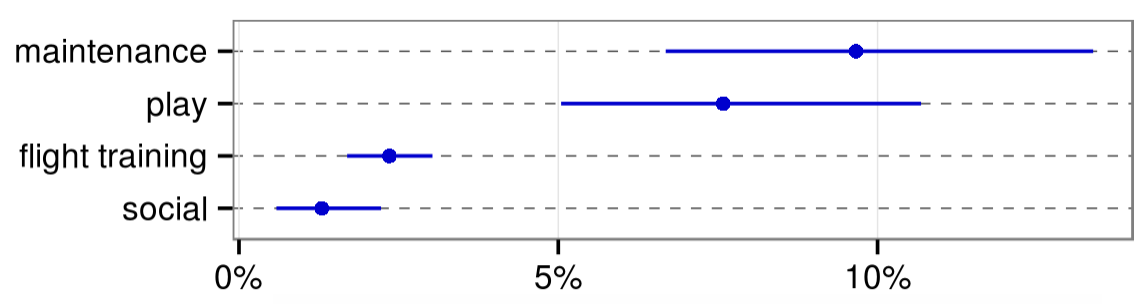

Figure 3. The proportion of the duration of the main behavioral categories out of total waking time (note the difference from Figure 1B, where sleep is included). The error bars show $95 \%$ bootstrap CIs.

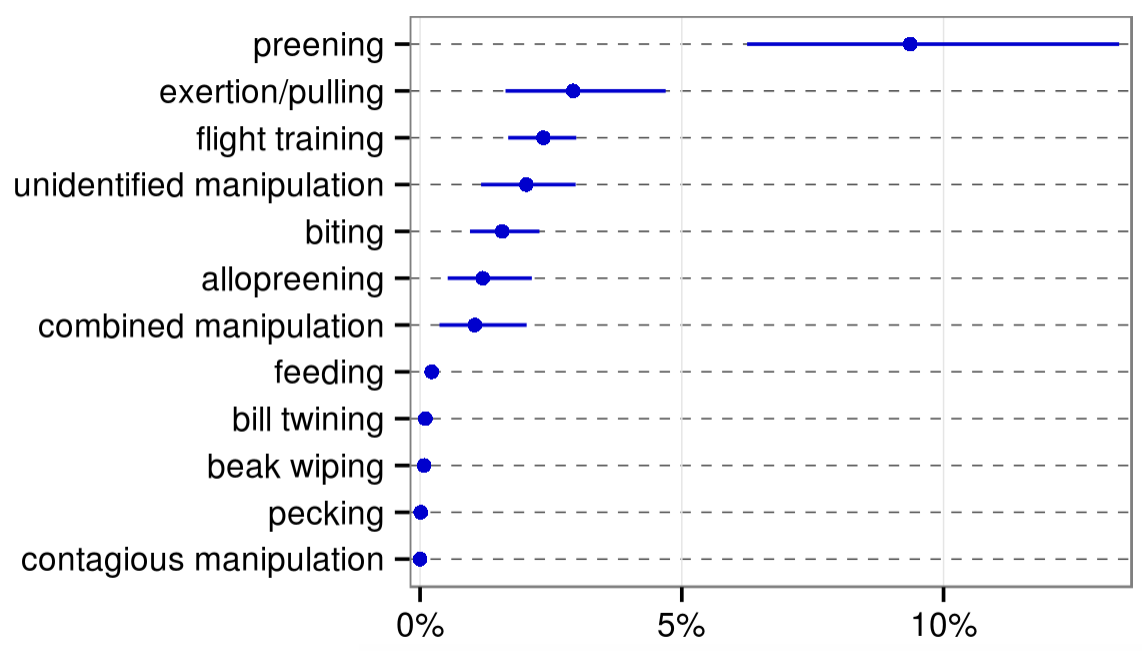

Figure 4. The proportion of durations of the sub-code out of total waking time (note the difference from Figure 2, where sleep is included). The error bars show $95 \%$ bootstrap CIs.

\section{Discussion}

Despite the limited nature of this study, the results suggest considerable levels of play in ravens toward the end of their nestling period. The raven chicks in principle had constant access to energy through the plentiful supply of nutritious food provided to their parents. This might have influenced the energy that could be spent on play and so raised the level of it (see Graham \& Burghardt, 2010). On the other hand, the unusually young parents had a complete lack of experience in rearing a brood and might have fed them less than optimally. Obviously, the frequency and duration of play may vary between different nests in different habitats. Nevertheless, even lower levels of play than we observed would indicate the importance of play to ravens' early development.

Heinrich and Smolker (1998) observed that flight training increased prior to fledging. They did not specify the period, and it might be that our observation window fell within it. However, we did not record an increase but a significant decrease in flight training. We observed a slight increase in play, which, already from the beginning, was more common than flight training. These differences could be artifacts of the small number of subjects; but, even without them, the high importance of play remains; one cannot doubt the value of flight training for a bird near fledging. 
Food caching is a central skill for most corvids including ravens. As said, some studies have investigated the ontogeny of caching in fledged ravens. One might ask whether any of the object play in the nest could be a precursor to caching. A nest is a constrained environment with few object-related options: the twigs are not loose but twined into a solid construction, while the lining is somewhat looser but still attached. Behaviors involving the placing of loose objects on or in other substrates have little opportunity to occur. Indeed, although codes for insertion and placing were included in our ethogram, not a single instance was recorded. The behavior that occurred most in terms of duration was exertion/pulling, this behavior was also part of combined manipulation and most likely also a large part of nondistinguishable manipulation. It would appear to be motorically the opposite of inserting or placing an object, as is characteristic of caching. Of course, when a chick yanked a twig backwards, there could have been moments of slight pushing as well, but such actions could not be distinguished. Although the object world surrounding very young ravens seems to contain few behavioral options other than pulling and pecking - so long as the nest material is intact - these options are used profusely. As noted, Bugnyar, Stöwe, and Heinrich (2007) did observe one raven nestling engaging in a pressing or placing behavior; this is the first caching-oriented behavior executed after fledging.

It seems that young ravens' object orientedness is strong and may precede any clear cachingrelated behavior. One might assume that general object-oriented motivation developmentally precedes motivations for performing caching-related behaviors. It has been suggested that such object-oriented, playful, exploratory motivations led to the innovation of caching in the early ancestors of corvids - a behavior later selected for (Jacobs et al., 2013).

Ravens' social skills are highly complex (see Bugnyar, 2013), and the social aspects of their play are clearly pertinent (Gwinner, 1966; Heinrich \& Smolker, 1998; Osvath \& Sima, this issue). This is seen already in the nest, where co-manipulation of an object occured relatively frequently (see Figure 5). Behavioral contagion seems already present in very young ravens. In our study, we found that some of the play behaviors were initiated immediately after another individual began the same type of manipulation. Such behavioral synchronization is regarded as an important function of social learning and might also be part of the basis for empathy (Preston \& de Waal, 2002; Zentall, 2001). Play appears to be contagious in both sub-adult and adult ravens (Gwinner, 1966; Osvath \& Sima, this issue). Ravens mimic novel forms of play invented by another individual (Gwinner, 1966): a process also observed in dolphins (Kuczaj et al., 2006).

Several of the object-play behaviors like pulling or biting a twig were strikingly similar to the pattern in allopreening. It is difficult to classify the subtle details of the different behaviors, and there might not be so many behavioral alternatives to biting or pulling a twig. Nevertheless, one can speculate about early common developmental mechanisms underlying parts of both social and object interaction. To investigate this, one needs to study the initial behaviors directed towards the world beyond the feeding parents.

This study could not determine the inception of play behavior in young ravens. However, we observed the first unambiguous play behavior, seen over the nest brim, 28 days after the first bird hatched (exertion/pulling). By contrast, infant chimpanzees (Pan troglodytes) have been observed to begin visually guided object manipulation by around 11-14 weeks of age (Potì \& Spinozzi, 1996). That said, there is a glaring sensorimotor difference in object manipulation between chimpanzees and ravens: the ape must coordinate its hands and eyes, whereas the bird's beak is always in the direction of its head implying that eye-appendage coordination should develop more quickly. This may affect early cognitive development: a young bird may have more sensorimotor feedback from the environment than a young mammal. However, the developmental sequences might still be similar.

To understand the underlying mechanisms of complex play, further, comparative studies following similar protocols should be conducted, looking at the early development of play behavior in corvids, parrots, great apes, and dolphins. Studies should also be conducted on both phylogenetically close and distant outgroups to these animals. The present study adds only one small piece of knowledge to this greater endeavor. 


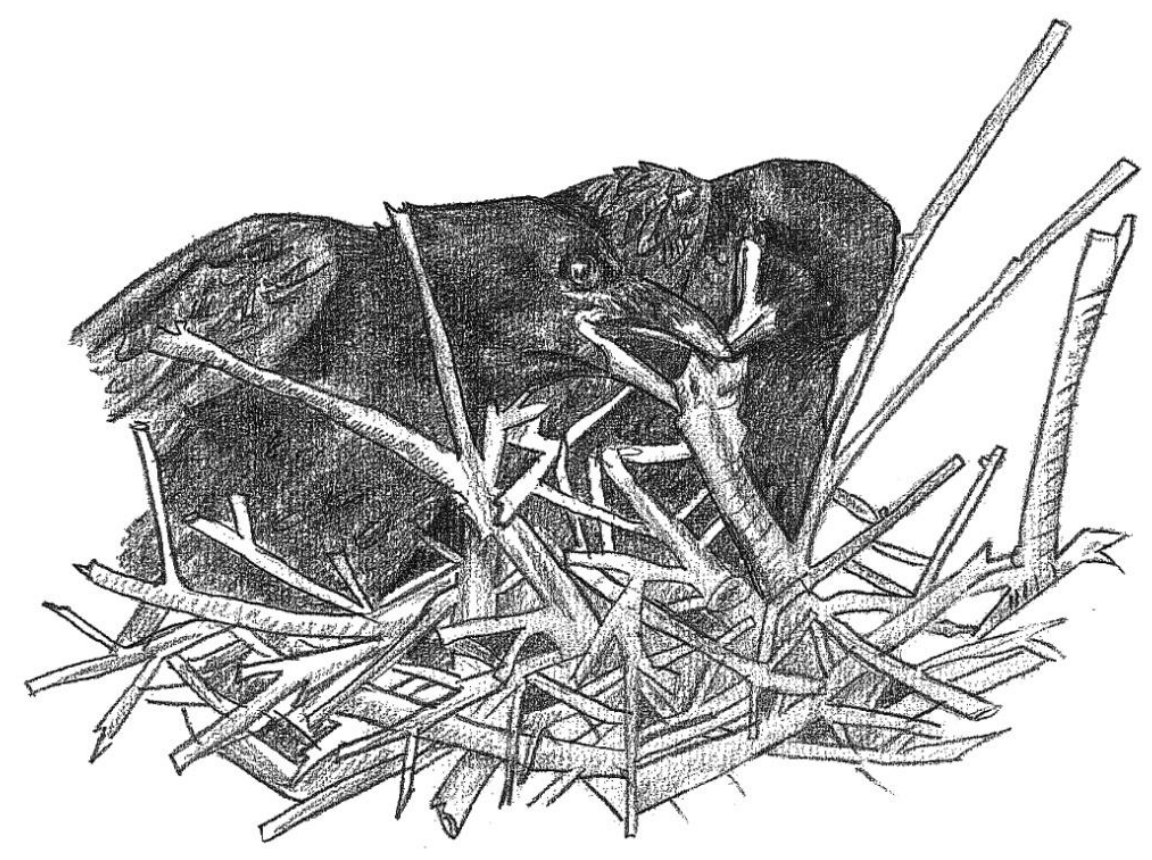

Figure 5. Two raven chicks engaged in co-manipulation of a twig. Co-manipulation occurred in $12.7 \%$ of the duration of all play behaviors.

\section{Acknowledgements}

We are grateful to Stan Kuczaj for inviting this paper. The Crafoord Foundation financed the main work. The Swedish Research Council, grant number 349- 2007-8695, supported Rasmus Bååth’s contribution.

\section{References}

Bakeman, R., Quera, V., \& Gnisci, A. (2009). Observer agreement for timed-event sequential data: A comparison of time-based and event-based algorithms. Behavior Research Methods, 41, 137-147. doi: 10.3758/BRM.41.1.137

Bugnyar, T. (2013). Social cognition in ravens. Comparative Cognition \& Behavior Reviews, 8, 1-12. doi:10.3819/ccbr.2013.80001

Bugnyar, T., Schwab, C., Schloegl, C., Kotrschal, K., \& Heinrich, B. (2007). Ravens judge competitors through experience with play caching. Current Biology, 17, 1804-1808. doi: org/10.1016/j.cub.2007.09.048

Bugnyar, T., Stöwe, M., \& Heinrich, B. (2007). The ontogeny of caching in ravens, Corvus corax. Animal Behaviour, 74, 757-767. doi: org/10.1016/j.anbehav.2006.08.019

Burghardt, G. M. (2005). The genesis of animal play: Testing the limits. London, UK: MIT-press.

Diamond, J., \& Bond, A. B. (2003). A comparative analysis of social play in birds. Behaviour, 140, 1091-1115. doi: $10.1163 / 156853903322589650$

Efron, B. (1979). Bootstrap methods: Another look at the jackknife. The Annals of Statistics 7, 1-26. doi:10.1214/aos/1176344552

Ficken, M. S. (1977). Avian play. The Auk, 94, 573-582.

Graham, K., L., \& Burghardt, G., M. (2010). Current perspective on the biological study of play: Signs of progress. The Quarterly Review of Biology, 85, 393-418. doi: 10.1086/656903 
Gwinner, E. (1966). Über einige Bewegungsspiele des Kolkraben. Zeitschrift für Tierpsychol. 23, 28-36. doi: 10.1111/j.1439-0310.1966.tb01587.x

Hassler, L. (2008). Raven soaring through history. Tucson, AZ: Rio Nuevo.

Heinrich, B., \& Smolker, R. (1998). Play in common ravens (Corvus corax). In M. Bekoff \& J. A. Byers (Eds.), Animal play: Evolutionary, comparative, and ecological perspectives (pp. 27-44). Cambridge, UK: Cambridge University Press

Iwaniuk, A. N., Nelson, J. E., \& Pellis, S. M. (2001). Do big-brained animals play more? Comparative analyses of play and relative brain size in mammals. Journal of Comparative Psychology, 115, 29-41. doi: 10.1037/0735-7036.115.1.29

Jaakkola, K. (2012). Cetacean cognitive specialization. In Vonk, J. \& Shackelford T. K., (Eds.), The Oxford handbook of comparative evolutionary psychology (pp. 144-165). New York, NY: Oxford University Press.

Jacobs, I. F., Osvath, M., Osvath, H., Mioduszewska, B., von Bayern, A. M. P., \& Kacelnik, A. (2013). Object caching in corvids: Incidence and significance. Behavioural Processes 102, 25-32 doi:10.1016/j.beproc.2013.12.003

Kenward, B., Schoegl, C., Rutz, C., Weir, A. A. S., Bugnyar, T., \& Kacelnik, A. (2011). On the evolutionary and ontogenetic origins of tool-oriented behaviour in New Caledonian crows (Corvus moneduloides). Biological Journal of the Linnean Society, 102, 870-877. doi: 10.1111/j.1095-8312.2011.01613.x

Kuczaj, S. A., Makecha, R.., Trone, M., Paulos, R. D., \& Ramos, J. A. (2006) Role of peers in cultural innovation and cultural transmission: Evidence from the play of dolphin calves. International Journal of Comparative Psychology, 19, 223-240.

Lorenz, K. (1959). Psychologie und Stammesgeschichte. In G. Heberer (Ed.), Die evolution der organismen, Bd 1. Stuttgart.

Marino, L. (2002). Convergence of complex cognitive abilities in cetaceans and primates. Brain, Behavior and Evolution, 59, 21-32. doi: 10.1159/000063731

Ortega, J. C., \& Bekoff, M. (1987). Avian play: Comparative evolutionary and develop-mental trends. Auk, 104, 338-341.

Osvath, M., \& Sima, M. (this issue). Sub-adult ravens synchronize their play: A case of emotional contagion? Animal Behavior and Cognition, 1(2).

Pellegrini, A. D., \& Smith, P. K.(2005). The nature of play: Great apes and humans. New York, NY: The Guilford Press.

Pellis, S. M. (1981). Exploration and play in the behavioural development of the Australian magpie (Gymnorthina tibicen). Bird Behavior, 3, 37-49. doi: 10.3727/015613881791560900

Pellis, S. M., \& Iwaniuk, A., N. (2004). Evolving a playful brain: A levels of control approach. International Journal of Comparative Psychology, 17, 92-118.

Pika, S., \& Bugnyar, T. (2011). The use of referential gestures in ravens (Corvus corax) in the wild. Nature Communications, 2, 560. doi: 10.1038/ncomms1567

Potì, P., \& Spinozzi, G. (1996). Early sensorimotor development in chimpanzees (Pan troglodytes). Journal of Comparative Psychology 108, 93-103.

Preston, S. D., \& de Waal, F. B. M. (2002). Empathy: Its ultimate and proximate bases. Behavioral and Brain Sciences, 25, 1-72. doi: 10.1017/S0140525X02000018

Seed, A., Emery, N., \& Clayton, N. (2009). Intelligence in corvids and apes: A case of convergent evolution? Ethology, 115, 401-420. doi: 10.1111\%2Fj.1439-0310.2009.01644.x

van Horik, J. O., Clayton, N. S., \& Emery, N. J. (2012). Convergent evolution of cognition in corvids, apes and other animals. In J. Vonk \& T. K. Shackelford (Eds.), The Oxford handbook of comparative evolutionary psychology (pp. 80-101). New York, NY: Oxford University Press.

Zentall, T. R. (2001) Imitation in animals: Evidence, function, and mechanisms. Cybernetics and Systems, 32, 5396. doi: $10.1080 / 019697201300001812$ 